\title{
Decifrando o Recado do Nome: uma Escola em Busca de sua Identidade Pedagógica*
}

\author{
Ana Chrystina Venancio Mignot
}

Universidade do Estado do Rio de Janeiro (UERJ)

Que é que é um nome? Nome não dá: nome recebe.

GUIMARÃES RosA

A análise da experiência de Armanda Álvaro Alberto na Escola Regional de Meriti - onde se desenvolveram os esforços iniciais pela integração escola-comunidade através da constituição do primeiro Círculo de Mães - , buscando conferir sentido ao projeto educacional renovador, apontou para uma questão menor e até mesmo negligenciável: a mudança sucessiva do nome da escola. Os nomes, enquanto expressão de uma dada identidade pedagógica que foi sendo construída, serviram de fio condutor para desfiar a trajetória de uma escola, de sua fundadora e companheiros da Associação Brasileira de Educação (ABE), e sua importância na comunidade caxiense, especialmente nos anos 20 e 30.

Investigar uma experiência pedagógica pioneira por seus métodos de ensino traz uma dupla exigência: caminhar pelas "pistas" e "zonas de sombra" da historiografia e, à moda de Sherlock Holmes, como propõe Cario Ginzburg (1989), buscar no caos empírico, numa fragmentação aparente, a possibilidade de reconstituir o trabalho desenvolvido em sua

-Texto resultante da pesquisa "Os Primeiros Passos na Busca da Integração Escola-Comunidade": a experiência pedagógica de Armanda Álvaro Alberto na Escola Regional de Meriti (1921 -1964), financiada pelo INEP, e apresentada na Reunião de Cooperação Técnicc-Científica na Área de História da Educação, promovida pelo INEP/MEC, em Belo Horizonte, em novembro de 1992. Este estudo contou com a carinhosa consultoria de Zaia Brandão. Participaram Mariza Reis Almeida, Elaine da Silva Mello e Roberta Andrade do Nascimento - estudantes da Faculdade de Educação da Baixada Fluminense/UERJ —, como auxiliares de pesquisa, de forma mais efetiva. 
complexidade. O desafio deste texto está na tentativa de desfiar uma trajetória escolar a partir de uma questão aparentemente menor, negligenciável, marginal: a mudança de nome de uma escola.

A Escola Regional de Meriti fundada por Armanda Álvaro Alberto, em Duque de Caxias, dando continuidade ao trabalho que havia desenvolvido em Angra dos Reis - uma escola para filhos de pescadores - teve originalmente, em 1921, o nome de Escola Proletária de Merity. Estranhamente, após dois anos de funcionamento, sua denominação foi modificada. Aliás, Robert Darnton (1986, p.xv) assinala:

... quando nao conseguimos entender um provérbio, uma piada, um ritual ou um poema, temos a certeza de encontrar algo. Analisando o documento onde ele é mais opaco, talvez se consiga descobrir um sistema de significados estranho. $\mathrm{O}$ fio pode até conduzir a uma pitoresca e maravilhosa visão de mundo.

Nome é enigma, máscara, mistério, sortilégio, magia, fardo, destino, voto, augúrio, vaticínio, índice, vestígio, marca, rótulo, diferença, particularidade, propriedade, projeto, eternização, atualização (Houaiss, 1976; Brandão, 1986; Machado, 1976). O nome é a "palavra com que se designa pessoa, animal, ou coisa (...) exprime uma qualidade característica ou descritiva (...) $\mathrm{O}$ nome próprio (é o) nome com que se nomeiam individualmente os seres e que se aplica em especial a pessoas, nações, povoações, montes, mares, rios etc." (Ferreira, 1975).

Nome confere identidade.

Nomear implica designar, proferir, chamar, criar, instituir, eleger, escolher. A escolha de um nome é sempre um ato de arbítrio, liberdade, manipulação, dominação. O nomeador - aquele que nomeia - está social e culturalmente condicionado ou motivado (Houaiss, 1976, p.11). O nome revela, além das características e qualidades do objeto nominado, a subjetividade ou posição social daquele que nomeia. Significativo, o nome significa o doador do nome, o nomeador (Machado, 1976, p.27).

Tentar decifrar os segredos contidos na mudança de nome de uma escola, envolve entender que um nome não existe sozinho. Faz parte de um contexto. Tem uma historicidade. A alteração do nome da escola 
servirá, portanto, de fio condutor através do qual se pretende apreender o sentido de um projeto educacional, em sua singularidade, projeto este que foi se tecendo num momento de introdução e difusão do ideário escolanovista no Brasil.

Nome de batismo: Escola Proletária de Merity

Nome de batismo sugere nascimento - um dado tempo e espaço. A Escola Proletária de Merity "nasce" em uma época anterior à difusão e à sistematização do ideário escolanovista no país. Examinando os antecedentes da Escola Nova no Brasil, Jorge Nagle concluiu que até 1920 o que se fez, em termos de renovação educacional, não passou de simples "preparação de terreno", havendo o estabelecimento de condições favoráveis ${ }^{1}$. Nesta "preparação de terreno" destacam-se desde os escritos de Rui Barbosa até as influências das escolas americanas, a reforma paulista e a criação de laboratórios de Psicopedagogia. Faz uma ressalva:

Ao traçar esse panorama dos antecedentes da introdução da Escola Nova no Brasil, estamos deixando deliberadamente de lado a menção da "escola ao ar livre", acidentalmente levada a funcionar em Angra dos Reis, cm 1919, sob a direção de Armanda Álvaro Alberto, onde se aplicou ao grupo de 50 alunos ali reunidos os ideais montessorianos de educação. Isso porque essa classe acidental se transformaria mais tarde, em fevereiro de 1921, na Escola Regional de Meriti, o que interessa, portanlo, ao período seguinte (Nagle, 1964, p.96).

A Escola Proletária de Merity pretendia ser um "laboratório de pedagogia prática" - característica de uma Escola Nova. Partia do interesse da criança, subvertendo o processo pedagógico centrado tradicionalmente no professor e abandonava as paredes da sala de aula para desenvolver

\footnotetext{
${ }^{1}$ Jorje Nagle (1964) considera que o processo de assimilação do ideário escolanovista no Brasil se deu em três fases principais: a primeira - preparatória - no final do período imperial até a segunda década deste século, quando ocorreram condições facilitadoras para posterior introdução do ideário, esboçando-se idéias, noções e procedimentos pedagógicos. A segunda — de difusão e sistematização - compreendeu o período de 1920 a 1930, onde as novas idéias educacionais se concretizaram em reformas da educação escolar A terceira fase, entre 1930 e 1934, caracterizou-se pelo embate ideológico com os católicos.
} 
atividades ao ar livre em contato com a natureza. Voltada para o ensinamento de hábitos de higiene que deveriam se propagar para a familia, não restringindo tal preocupação ao espaço interno da sala de aula, a escola envolvia a comunidade. O seu projeto arquitetônico - atribuído a Lúcio Costa revelava também a preocupação com esta integração:

...um estilo pronunciadamente doméstico e que tudo faz para ser chamada escola-casa de família, freqüentada diariamente pelas mães dos alunos, que por sua vez, são procuradas pela professora-visitadora (Sussekind de Mendonça, 1968, p. 17).

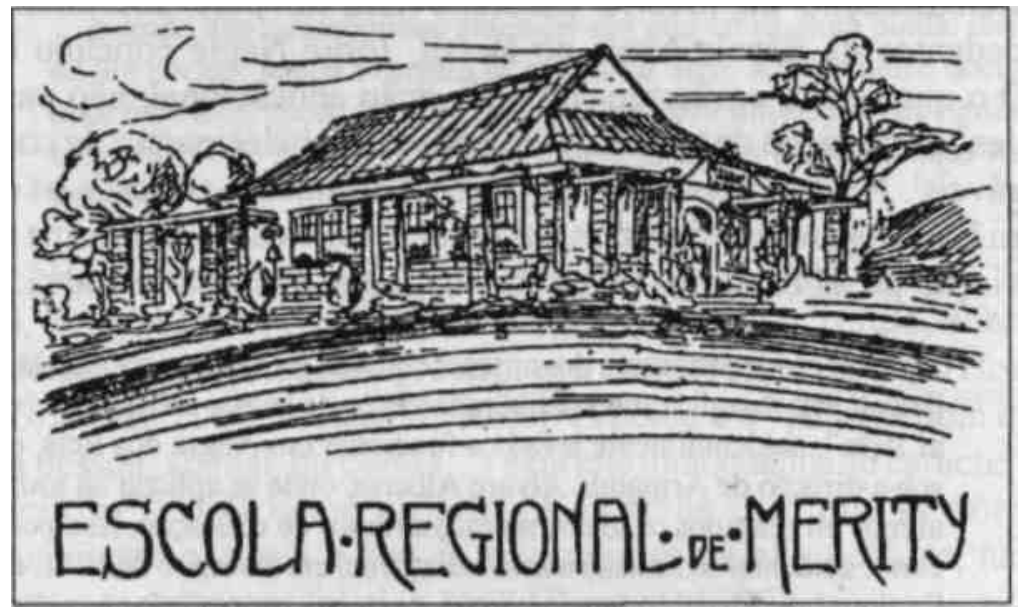

Fig. 1 - Escola Regional de Meriti. Projeto de construção do arquiteto — Lúcio Costa e prédio inaugurado em 1928. (Informação contida no trabalho de Edgar Sussekind de Mendonça - A Escola Regional de Meriti (Realizações e Projetos), publicado na obra de Armanda Álvaro Alberto, pelo MEC, 1968).

Fonte: MORAES, Dalva Lazaroni de. Esboço histórico-geográfico do município de Duque de Caxias. Duque de Caxias: Arsgráfica, 1978, p. 136B.

Nome de batismo confere uma identidade. Projeta sonhos, desejos e expectativas dos nomeadores. Sinaliza a função que se esperava que a escola viesse a desempenhar. Proletário deriva do "latim proletariu (Ferreira, 1975) 'cidadão pobre, útil apenas pela prole, isto é, apenas pelo 
filho que gerava'. Na Roma antiga, cidadão pobre, pertencente à ultima classe do povo. Homem pobre que vive do seu salário". O nome "proletária" expressa que pretendia ser uma escola para o povo.

Desde o início de seu funcionamento, este ensaio de escola moderna não tinha "modelo a seguir", "programa escrito", "prêmios e castigos", "férias completas" (Álvaro Alberto, 1968, p.36). Constituiu-se uma escola essencialmente popular porque "considera a criança pobre a sua gente favorita" (Sussekind de Mendonça, 1968, p.17) tomando por "base essencial de seu programa educar crianças do povo, preparando-as para viver no seu meio e no seu tempo" (Venancio Filho, 1968, p.25).

Mas, se não tinha modelo a seguir, reiteradamente aparece tanto nos escritos de Armanda Álvaro Alberto como nos depoimentos sobre o funcionamento da escola a grande influência que recebeu ${ }^{2}$, do ponto de vista estritamente pedagógico, de Montessori:

Tendo observado de perto, em convivência longa, vários gnupos de população brasileira do centro e nordeste do país, sempre interessada pelos problemas de educação no Brasil, aproveitei uma estadia de muitos meses numa praia de Angra dos Reis, em 1919, a primeira oportunidade que se me oferecia para ensaiar uma escola. Apareceram prontamente cerca de 50 crianças, para as quais não existia escola pública ou particular, por toda a redondeza. Não tendo coragem de rejeitar nenhum desses alunos que iam dos 3 aos 16 anos, organizei as turmas com a homogeneidade possível em tais circunstâncias, e pus-me a praticar o que estudara nos livros de Montessori (Álvaro Alberto, 1968, p.35).

Inspirada a princípio em Montessori, Armanda Alberto organizou, em breve, um sistema próprio, visando não só à educação das crianças, mas a dos pais dos alunos, problema muito particular às nossas populações rurais e que

\footnotetext{
${ }^{1}$ Edgard Sussekind de Mendonça (1968, p 18). com quem viria a se casar, aponta as seguintes influências pedagógicas sôbre Armanda Álvaro Alberto: "A Casa dei Bambini de Maria Montessori e Murmure de George Lcroy, dois livros inspiradores da fundadora da Escola, foram presentes oportunos de dois grandes educadores: Francisco Venancio Filho e José Piragibe". Paschoal Lemme (1988, p. 138) observa influência de outra natureza: "Mas, a obra de LV Armanda, nascida sob a inspiração de Euclides da Cunha, e isso já era um programa de seriedade, de devoção, de profunda compreensão do homem brasileiro, de sadio nacionalismo, pode, como era natural, interessar às maiores figuras, os verdadeiros apóstolos dessas causas" Pretendo examinar esta questão em próximo estudo quando, a partir de Armanda Álvaro Alberto, estudarei a educação pela mulher no movimento de renovação educacional, em tese de doutorado sob a orientação de Margarida de Souza Neves.
} 
não lhe escapou ao espírito. A escola organiza campanhas de higiene, concursos de trabalhos e de arte, entre os moradores da localidade, e abre sua biblioteca à população. Foi a primeira escola a fundar, no Brasil, ura "Círculo de Mães", não só para maior coordenação do trabalho da escola com o da família, mas também para disseminação dos conhecimentos de higiene e educação doméstica (Lourenço Filho, 1978, p.176).

O nome de batismo da escola - Escola Proletária - teria sido inspirado na obra de Montessori. Armanda Álvaro Alberto, no entanto, fundamentou-se nos princípios e não, propriamente, no método e emprego de materiais pedagógicos específicos. A primeira das Casas das Crianças surgiu, em 1907, dentro de um projeto de saneamento dos bairros populares de Roma, visando construir casas salubres para os operários. Coube a Maria Montessori desenvolver o trabalho educativo dos seus filhos. Acreditando na função redentora da educação infantil, imprimiu à sua tarefa uma dada direção: "interessando a responsabilidade e a boa vontade de todos os pais coabitantes na higiene e no desenvolvimento da escola, habituando-os a interessar-se pela educação dos filhos" (Calo, 1978, p.306).

Mas, o nome de batismo sugere mais que uma escola para o povo. Indica pertencimento a um lugar: Merity. A escolha do local tinha um significado, significado este sinalizado por Edgard Sussekind de Mendonça (1968, p.21):

Não foi para constituir um exemplo de perfeição ou mesmo de apurada qualidade, mas foi para constituirmos um exemplo de possibilidade de realização, que mais valesse porque nos cercamos, justamente, das menos vantajosas das condições locais.

A Baixada Fluminense - região escolhida por Armanda Álvaro Alberto para fazer funcionar a escola - era àquela época zona rural ${ }^{3}$. Na ocasião da instalação da escola, a região era constituída por um único

${ }^{5}$ Apesar de o termo Baixada Fluminense compreender, do ponto de vista geográfico. Baixada de Goitacazes, Baixada de Araruama, Baixada de Guanabara, Baixada de Sepetiba, hoje, ao se designar Baixada Fluminense está sendo feita referência à região da Baixada de Guanabara, próxima ao Rio de Janeiro, englobando os municípios de Nova Iguaçu, Duque de Caxias, São João de Meriti, Nilópolis, Belford Roxo, Queimados, Japeri e Mage. 
município - Iguaçu, foi desdobrada e na banda leste de seu território, com base na estação ferroviária de Meriti, acabou sendo criado em 1931 o distrito de Duque de Caxias, que se converteu em município em 1943 (Beloch, 1986, p. 17).

O cenário onde se desenvolveu o trabalho pedagógico de Armanda Álvaro Alberto e seus colaboradores foi descortinado nos relatórios anuais. A Baixada Fluminense, em 1921, vivia em declínio econômico, faltava saneamento, proliferavam charcos insalubres e doenças como a malária - resultado do descaso governamental nos primeiros anos da República.

Os relatórios registravam, ao longo dos anos, não só as dificuldades e conquistas pedagógicas mas revelavam, sobretudo, as condições de vida da comunidade. Epidemias de sarampo, coqueluche, casos de tuberculose, surtos de impaludismo, conviviam com ausência de Posto de Profilaxia Rural, guarda sanitário, vacinas, medicamentos, assistência médicoodontológica, água encanada, rede de esgotos, instalações sanitárias, iluminação e transporte. Assinalavam ainda o aumento populacional, a miséria e a violência decorrente da ocupação de terras a partir de 1930. Ao encerrar suas atividades à frente da escola, em 1964, o quadro traçado por Armanda Álvaro Alberto nos relatórios escolares, ao longo dos anos, permanecia dramático. Estudo realizado por Janice Perlman (1977, p.78-79) sobre Duque de Caxias, na década dos 60, evidenciou que os serviços urbanos não eram quantitativa e qualitativamente melhores que os oferecidos nas favelas das zonas sul e norte de Rio de Janeiro:

Apenas 17 por cento dos moradores entrevistados dispunham de água encanada (...) Cerca da metade das moradias de Caxias (...) não tinha banheiros dentro ou junto das casas; e apenas 45 por cento da área era servida de rede de esgotos. A quarta parte das casas não dispunha de eletricidade. Tão-somente a metade dos 23 bairros de Caxias, que tecnicamente não são favelas, tinham suprimento público de água.

O nome de batismo confere, portanto, a identidade de uma escola que se pretendia renovadora. Em sintonia com o movimento renovador que surgia em outros países, desenvolvia processos pedagógicos - tanto no que se refere à organização geral como no que diz respeito à formação 
intelectual e moral - muito semelhantes àqueles que em 1919, em Calais, foram definidos como "caracteres gerais das 'escolas novas no campo', ou seja, da escola nova em seu sentido original" 4 .

\section{Escola Regional de Meriti: nome que consagra}

O nome próprio é emblemático. Denota, conota, evoca, indica, significa. Nomes mudam, flutuam, simbolizando travessia, desintegração, desagregação, inauguração. $\mathrm{O}$ nome próprio "encerra e cristaliza várias sentenças potenciais ou latentes que vão se revelando, manifestando, atualizando o que estava só guardado e escondido de maneira cifrada" (Machado, 1976, p.64).

Mudanças de nomes envolvem rituais, cerimônias, personificação de novos papéis ${ }^{5}$. Neste caso, os arquivos revelam que esta mudança de nome estava posta desde o primeiro ano de funcionamento. No relatório de atividades anuais, de 1921, Armanda Álvaro Alberto (apud Moraes, 1978, p. 132-133) previa a alteração do nome da escola:

Inaugurada a 13 de fevereiro deste ano, a nossa Escola conta hoje dez meses e doze dias de existência (...) Estamos certos, nós c nossos companheiros do Comitê, que a Escola se desenvolverá normalmente. Tanto a nossa atitude é ainda de quem não atingiu a sua meta - que o nome definitivo, Escola "Álvaro Alberto", em homenagem à memória do Dr. Álvaro Alberto da Silva, seu Patrono, só lhe será conferido quando a virmos mais próxima do tipo que idealizamos. Esforçamo-nos por que venha a ser uma acabada "escola regional"; afeiçoada pelo seu próprio meio é que será capaz de agir eficazmente sobre ele.

Recortes de jornais, impressos, correspondências, publicações fazem menção ao fato de que anteriormente teria tido um outro nome.

\footnotetext{
${ }^{4}$ A este respeito consultar Lourenço Filho (1978, p. 162), quando reproduz documento contendo as características que deveria possuir uma escola nova. A Escola Proletária de Mcrity 'atendia às seguintes características: pretendia ser um laboratório de pedagogia prática; estava situada no campo, próxima a uma cidade, valorizava trabalhos manuais com finalidade educativa; privilegiava o ensino de marcenaria, jardinagem e criação de animais, priorizava o trabalho coletivo, o ensino baseado em fatos e experiências; promovia visitas; preocupava-se com a beleza do ambiente e em particular com a ordem e a higiene.

${ }^{5}$ Consultar Carlos Rodrigues Brandão (1986), especialmente os capítulos que abordam papéis, personagens e nomes sociais na análise da construção da identidade.
} 
Uma referência mais clara está no relatório anual de 1923 (p. 1), registrando a alteração como uma decorrência natural. Uma simples metamorfose:

... todos aquelles que acompanharam a vida desta casa sabem que o nome que lhe demos ao surgir - Escola Proletária de Merity - era um nome provisório, e que outro, grato ao nosso sentimento filial lhe era destinado bem a víssemos florescente, "afeiçoada pelo seu próprio meio e capaz de reagir eficazmente sobre elle" - em summa, com os seus traços bem definidos, livre das incertezas dos primeiros tempos.

A alteração do nome sugere que a identidade foi se constituindo. Aos poucos a escola foi "lançando raízes profundas no seu meio social", "desenvolvendo sua ação na vida local", onde se justificavam atividades que envolvessem a comunidade. Campanhas de saneamento, através de conferências populares no cinema local e a criação, em 1925, do Círculo de Mães. Este círculo desenvolvia programas para "aquelas mães analfabetas em sua maioria; higiene, educação familiar e economia doméstica" preparando a "cooperação que sonhamos das famílias com a Escola" (Álvaro Alberto, 1968, p.37).

A escola colaborava com as famílias das mais variadas formas: "desde enfermidades até litígios entre senhorio e o inquilino" (Venancio Filho, 1968, p.27). Eram realizadas visitas domiciliares e as famílias recebiam boletins mensais onde não constavam notas, mas estavam relatadas as atividades dos alunos, exames de saúde e os atos de bondade. À escola cabia dar assistência geral: educação gratuita mais merenda, vestuário, calçado, assistência médica e remédios (Álvaro Alberto, 1968, p.39).

O novo nome não significava uma ruptura com o projeto anterior. Proletária não era mais suficiente para esclarecer o que se pretendia com uma escola para o povo. Mas, se a identidade é "aquilo que torna específicos, irredutíveis a outra coisa" (Distante, 1988, p.80), ela passa pela diferença. É uma diferença. Não é dada. A identidade existe em "função de uma trajetória com opções mais ou menos dramáticas" (Velho, 1988, p. 119). O nome Regional traduz uma trajetória de busca de identidade estabelecida enquanto especificidade e diferença. 
A mudança de nome demonstrava que o objetivo dos fundadores era aliar a educação popular à educação regional, isto é, a regionalização do ensino, tomada como "preceito metodológico e social", concebia que a "vida local não influi na escola só para dar rumo das atividades educativas. A região constitui a coleção de temas mais apropriados às atividades das aulas" (Sussekind de Mendonça, 1968, p.20). A integração escolacomunidade obedecia assim à compreensão de que a "educação primária de todas as crianças e do povo é dominada pelo interesse da vida local" (Sussekind de Mendonça, 1968, p.14).

Mas a mudança de nome ao significar o doador do nome, pode indicar o processo de constituição da identidade do grupo nomeador. Sinaliza, assim, que a identidade do grupo foi se construindo e se revelando através da escola.

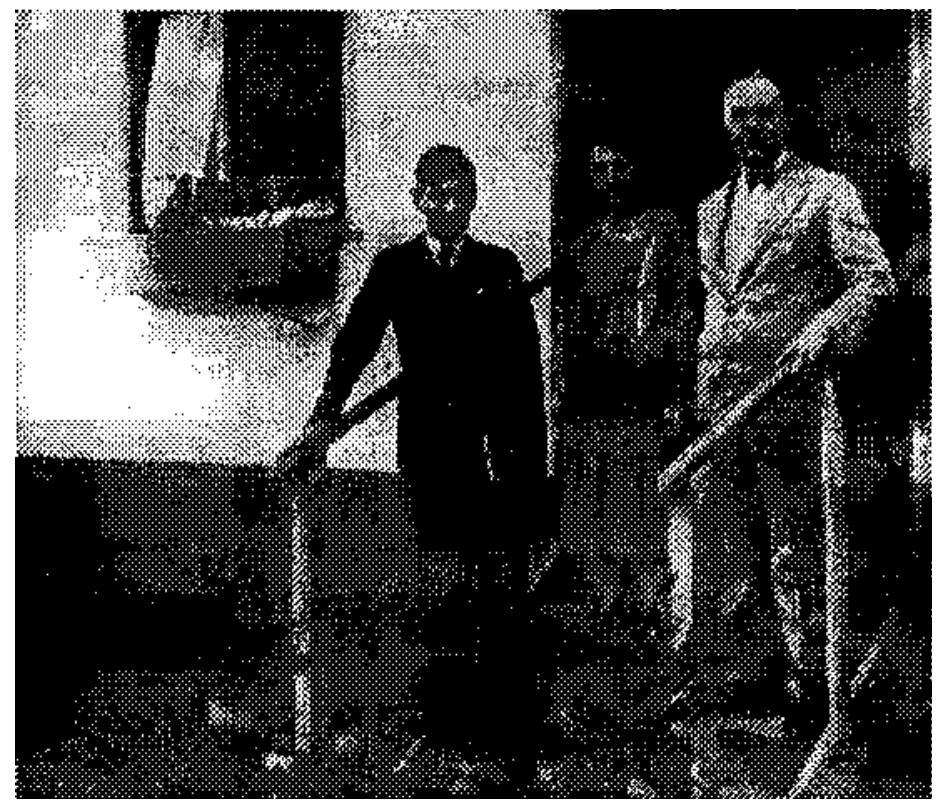

Francisco Venancio Filho, Armanda Álvaro Alberto e Edgard Sussekind de Mendonça, na inauguração do prédio da Escola Regional de Meriti, em 24 de junho de 1928. Foto de acervo privado de Armanda Álvaro Alberto. 
Estudo de Marta Chagas de Carvalho, inventariando as diferenças, mapeando as polêmicas no interior da $\mathrm{ABE}$, entre 1924 e 1931, traz à tona a existência de um grupo à parte que, dentro da entidade, divergia do pensamento educacional dominante. Este grupo era formado por Armanda Álvaro Alberto, Edgard Sussekind de Mendonça e Francisco Venancio Filho:

Não defendiam a centralização do ensino, distanciando-se dos dois outros grupos. Eram em 20, reticentes quanto à interferência do Estado na educação. Eram laicistas, opondo-se às investidas do grupo católico que, seja no Conselho Diretor, seja nas Conferências Nacionais, atualizava o catolicismo como ingrediente indescartável da "educação integral" receitada consensualmente na Associação. Reagiam também às investidas de Laboriau no sentido de agregar a campanha educacional ao movimento político partidário, reticentes principalmente à vinculação deste com o Clube dos Bandeirantes do Brasil (Carvalho, 1988, p.8).

A polarização do debate no Conselho Diretor da entidade dava-se em torno de algumas questões básicas: regionalização $\mathrm{x}$ uniformização do ensino; orientação leiga $x$ religiosa e competência estatal em matéria de educação (Carvalho, 1986, p. 149). Rejeitavam a presença estatal na educação porque viam no Estado uma "presença nefasta porque dissociadora da relação escola-meio ambiente e inibidora de um trabalho inovador" (Carvalho, 1986, p. 153), presença esta que trazia maiores prejuízos quando se tratava de atender, no ensino rural, às populações mais pobres.

Edgard Sussekind de Mendonça considerava despropositada a importância atribuída à educação como instrumento de unidade nacional e o Estado com um papel unificador, como defendiam Fernando Magalhães e Ferdinando Laboriau e seus respectivos grupos. Esperava que a Escola Regional preparasse a Escola Nacional, pois só compreendia a nacionalidade que incorporasse as linhas características da região. Para ele, a unidade nacional seria conquistada graças a "iniciativas que adotassem a regionalização do ensino como preceito de ordem metodológica e social e não o resultado de uma política estabelecida de 
antemão, imposta por normas emanadas do Estado" (Carvalho, 1986, p.156).

Se para Fernando Magalhães a promoção da unidade nacional era objetivo da política educacional voltada para a zona rural, e a regionalização do ensino entendida apenas como possibilidade de adaptação ao meio, capaz de "formar 'o mesmo brasileiro' para todo o país, na Escola Regional de Meriti, a adaptação à vida regional era vista como caminho para permitir ao aluno acesso à cultura, patrimônio dos instruídos" (Carvalho, 1986, p.164).

Regional sintetizava, sobretudo, a compreensão de que a nacionalidade era resultante da incorporação das diferenças e que o regional era expressão do nacional ${ }^{6}$ :

A escola primária tem que ser regional, o que não a impede de ser brasileira. Tanto melhor reagirá sôbre o seu meio, quanto mais adaptada lhe estiver. Na roça é o único centro, muitas vezes, da vida intelectual; deve sentir as necessidades de progresso de sua região e tomar a si as iniciativas em beneficio da comunidade a que pertencem os seus alunos (Álvaro Alberto, 1968, p.41).

A Escola Regional de Meriti representou, assim, uma alternativa, um "ponto de referência importante na reflexão da $\mathrm{ABE}$ sobre educação popular, como experiência de utilização da chamada 'escola ativa' em projetos de regionalização do ensino do país" (Carvalho, 1986, p. 151152). O novo nome - Regional - foi, portanto, o nome que deu nome. $\mathrm{O}$ nome que consagrou uma experiência em sua especificidade e um grupo que se constituiu na diferença.

\section{O nome que fica porque significa}

Nome evoca, determina, alude, evidencia. Nome traduz origem, filiações, pertencimentos, segregações. Nome de batismo sugere tempo e espaço. Nome dá nome. Nome revela cerimônia e intimidade. ${ }^{6}$ Ver estudos de Lúcia Lippi de Oliveira (1990) e Renato Ortiz (1985) sôbre o debate intelectual em tomo da concepção de
naç5o. 
O nome "indica a função que desempenha na trama" (Machado, 1976, p.167). Assim, ao se despedir da escola, em 1964, transferindo-a para o Instituto Central do Povo - após tentativa frustrada de repassá-la para a administração pública estadual —, Armanda Álvaro Alberto solicita que a escola se chame Escola Dr. Álvaro Alberto - uma homenagem ao seu pai. Este pedido, na cerimônia de despedida, exprime a compreensão de que, a partir daquele momento, inaugurava-se uma outra etapa de vida da escola. Missão cumprida, objetivos atingidos, o nome previsto, desde o primeiro ano de funcionamento, é dado, finalmente, à escola.

$\mathrm{O}$ nome Escola Regional de Meriti consagra a experiência. Na memória erigida por Fernando de Azevedo (1944, p.127) sobre o movimento renovador ${ }^{7}$, no Brasil, este trabalho figura junto a outros desenvolvidos nos anos 20:

Não faltavam aqui e ali iniciativas particulares como para citar uma das primeiras e de sentimento mais corajosamente renovador, a Escola Regional de Meriti; fundada no Estado do Rio de Janeiro, em 1921, por Armanda Álvaro Alberto, que se alistava entre os pioneiros da educação nova no Brasil.

Escola Regional de Meriti é o nome que revela a reverência dos pares de Armanda Álvaro Alberto ao seu trabalho pedagógico. Escola de "admirável intenção socializadora", preocupada em "educar crianças do povo" e "nascida do ideal e do sonho, mas forjada na luta com a prática e com a realidade" — testemunham ainda Lourenço Filho, Venancio Filho e Paschoal Lemme (cf. Álvaro Alberto, 1968).

Nome também rompe distâncias propondo intimidade. Em que pese o empenho dos fundadores da escola em buscar um nome próprio mais afinado com o projeto pedagógico que empreendiam, o nome que evoca lembranças dos antigos colaboradores, ex-alunos e ex-professores não é nem o nome de batismo nem o que a consagrou.

' Consultar lese de doutoramento de Zaia Brandão (1992), quando analisa as memórias e as histórias da educação brasileira sôbre o movimento renovador. 


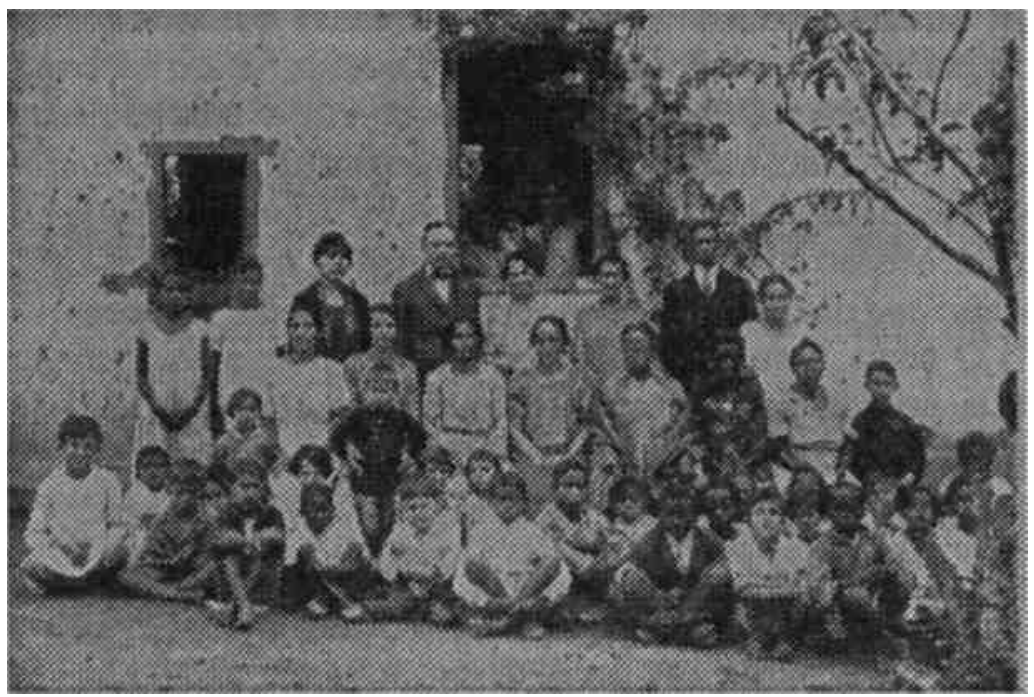

"Num dia como os outros... mücs, alunos e professores" é o título desta foto. Ao fundo, Edgard Sussekind de Mendonça e a diretora, entre professores de economia doméstica e trabalhos manuais, alguns alunos e mães do Círculo de Mães da Escola Regional de Meriti, 15 de outubro de 1926. Álbum fotográfico do acervo privado de Armanda Álvaro Alberto.

O nome que ficou foi um apelido que foi dado pela comunidade escolar. Apelidar também é designar, denominar. Neste caso, denota trato carinhoso destacando uma característica inconfundível. O nome pelo qual a escola de Armanda Álvaro Alberto foi "batizada" pela comunidade indica que esta tomou posse da escola pelo que ela tinha de mais forte - a assistência, através da distribuição de material, merenda e vestuário. Uma ex-aluna e antiga professora da escola - Maria José Trindade Dutra recorda:

As crianças, todas carentes, chegavam pela manhã e já encontravam um tabuleiro de angu doce e um latão cheio de mate, que lhes era oferecido. Foi 
a partir daí que surgiu a idéia da merenda escolar \{Informe Educar, 1989, p.4).

Outros ex-alunos e antigos colaboradores lembram também:

Hoje, fala-se muito em CIEP, em alimentação para os alunos, 3 ou 4 (...) Aqui em Duque de Caxias já existia este critério da alimentação através da Escola Regional de Meriti (...) que oferecia comida aos alunos no horário de 10 horas e no horário das 2 horas (José Damásio - ex-aluno entrevistado).

Tive muita oportunidade de conversar com D. Armanda (...) muitas vezes (...) me convidava para ir à casa dela para conversarmos com mais detalhes sobre a Escola (...) Estava querendo saber sempre alguma coisa e até mesmo fazer alguma coisa em benefício das crianças, daquelas menos favorecidas que os pais tinham dificuldade para mandá-las para a escola porque faltava um sapatinho, uma roupa (...) Ah! Sr. Monte, faz o favor de me levar isto para Judith ou para Carminha ou pra Maria enfim... era assim ... (José Monte, antigo colaborador, professor de carpintaria que atua ainda hoje na escola).

\section{Aliás, a comunidade tão valorizada por Armanda Álvaro Alberto e seus colaboradores resistia em alguns momentos à experiência, como destacou Yvonne Jean (1948, p.48-49):}

Mas os esforços da Escola de Meriti são pouco apreciados na região. Outro dia, ainda, um vizinho ficou indignado porque os alunos estavam consertando cadeiras no jardim. Gritou que daria queixa aos jornais porque nenhuma escola tinha o direito de obrigar as crianças a "trabalhar". A educação geral dos habitantes é péssima e suas idéias das mais atrasadas. Imagino que, muitas vezes, D. Armanda põe as mãos na cabeça, pensando: 'Os esforços e sacrifícios de vinte e seis anos seguidos teriam dado um resultado compensador?

Anos depois, esta resistência ficou minimizada, como demonstram os depoimentos. Eles são também expressão de silêncio. Há de se considerar que os colaboradores, alunos e professores de uma escola criada em 1921, já têm uma idade avançada, suas lembranças estão atualizadas e sujeitas, como diz Ecléa Bosi (1979) sobre as lembranças dos velhos, à 
pressão dos preconceitos e às suas preferências. Esquecem aquilo que não é atualmente significativo. No entanto, o limiar do esquecimento e do silêncio é tênue. Pollak (1988, p.8), a este respeito comenta: "... existem nas lembranças de uns e de outros zonas de sombra, silêncio, 'não ditos'. As fronteiras desses silêncios e 'não ditos' com o esquecimento definitivo e o reprimido inconsciente não são evidentemente estanques e estão em perpétuo deslocamento". Os testemunhos abafam as antigas críticas e ressaltam o cotidiano da escola, as festas, o empenho de D. Armanda, e sua dedicação às crianças.

Como na memória "só fica o que significa", também o nome que permaneceu foi aquele que, para a população, definia melhor a identidade da escola. O nome Escola Proletária ou Regional tinha sentido para seus fundadores. O último nome - Dr. Álvaro Alberto - também representava para Armanda Álvaro Alberto a conquista de uma meta e o início de uma nova etapa. Mas, o nome que ficou na memória, até hoje, foi o atribuído pela comunidade, como relembrou Raquel Trindade, representando os ex-alunos, por ocasião da festa de despedida de D. Armanda (1968, p. 173):

Quando estive na Europa, me mostraram métodos de ensino adiantadíssimos. Os Senhores não imaginam o que senti quando verifiquei que os métodos da escola que o povo chamava de mate com angu estavam além dos métodos europeus. Mate com angu era como nos chamavam na rua, mas eles sabiam que nós não ligávamos para o apelido, não ligávamos porque éramos felizes.

Referências bibliográficas

ÁLVARO ALBERTO, Armanda. A Escola Regional de Meriti (documentário): 1921-1964. Rio de Janeiro: MEC, INEP, CBPE, 1968.

AZEVEDO, Fernando de. A cultura brasileira. São Paulo: Ed. Nacional, 1944.

BELOCH, Israel. Capa Preta e Lurdinha - Tenório Cavalcanti e o povo da Baixada. Rio de Janeiro: Record, 1986.

BRANDÃO, Carlos Rodrigues. Identidade e etnia: construção da pessoa e resistência cultural. São Paulo: Brasiliense, 1986. 
BRANDÃO, Zaia. A Intelligentsia Educacional: um percurso com Paschoal Lemme por entre as memórias e as histórias da Escola Nova no Brasil. Rio de Janeiro, 1992. Tese (Doutorado) — PUC-RJ.

BOSI, Ecléa. Memória e sociedade: lembrança de velhos. São Paulo: T.A. Queiroz, 1979.

CALO, Giovanni. Maria Montessori (1870-1952). In: CHÂTEAU, Jean. Os grandes pedagogistas. São Paulo: Ed. Nacional, 1978.

CALVINO, ítalo. As cidades invisíveis. São Paulo: Cia. das Letras, 1990.

CARVALHO, Marta Maria Chagas de. Molde nacional e forma cívica: higiene, moral e trabalho no projeto da Associação Brasileira de Educação (19241931). São Paulo, 1986. Tese (Doutorado) — USP.

. Notas para reavaliação do movimento educacional. Cadernos de Pesquisa, São Paulo, n.66, 1988.

DARNTON, Robert. O beijo de Lamourette: mídia, cultura e revolução. São Paulo: Cia. das Letras, 1990.

. O grande massacre dos gatos. Rio de Janeiro: Graal, 1986.

DISTANTE, Carmelo. Memória e identidade. Tempo Brasileiro, Rio de Janeiro, n.95, 1988.

FERREIRA, Aurélio B.H. Novo dicionário da língua portuguesa. Rio de Janeiro: Nova Fronteira, 1975.

FORTES, Do Carmo Cavalcanti. Tenório: o homem e o mito. Rio de Janeiro: Record, 1986.

GEERTZ, Cliford. A interpretação das culturas. Rio de Janeiro: Zahar, 1978.

GOMES, Angela de Castro, FERREIRA, Marieta de Moraes. Primeira República: um balanço historiográfico. Estudos Históricos, Rio de Janeiro, v.2,n.4, 1989.

GINSBURG, Cario. Mitos, emblemas e sinais: morfologia e história. São Paulo: Cia. das Letras, 1989. cap.: Sinais: raízes de um paradigma indiciário.

HALBWACHS, Maurice. A memória coletiva. São Paulo: Vértice, 1990.

HOUAISS, Antonio. Prefácio que devia ser Posfácio. In: MACHADO, Ana

R. bras. Est. pedag., Brasília, v.74, n.178, p.619-638, set./dez. 1993 
Maria. Recado do nome: leitura de Guimarães Rosa à luz do nome de seus personagens. Rio de Janeiro: Imago, 1976.

JEAN, Yvonne. Visitando escolas. Rio de Janeiro: Ministério da Educação e Saúde, Serviço de Documentação, 1948.

LEMME, Paschoal. Memórias. São Paulo: Cortez; Brasília: INEP, 1988 v.3, cap. 11: A Escola Regional de Mcriti no $40^{\circ}$ aniversário de sua fundação (uma experiência brasileira de educação).

LOPES, Eliane M.T. Fontes documentais e categorias de análise para uma história da educação da mulher. Belo Horizonte, 1992. mimeo.

LOURENÇO FILHO, M.B. Introdução ao estudo da Escola Nova. São Paulo: Melhoramentos: FNME, 1978.

LOURO, Guacira L. A história (oral) da educação: algumas reflexões. Em Aberto, Brasília, v.9, n.47, p.21-28, jul./set. 1990.

MACHADO, Ana Maria. Recado do nome: leitura de Guimarães Rosa à luz do nome de seus personagens. Rio de Janeiro: Imago, 1976.

MORAES, Dalva Lazaroni. Esboço histórico-geográfico do município de Duque de Caxias. Duque de Caxias: ARS, 1978.

NAGLE, Jorge. Introdução da Escola Nova no Brasil (antecedentes). Boletim de Teoria Geral da Educação, Araraquara, v. 1, n.2, 1964.

NAMER, Gérard. Mémoire et société. Paris: Meridiens Kiincksicck, 1987.

NUNES, Clarice. Anísio Teixeira: a poesia da ação. Rio de Janeiro, 1991. Tese (Doutorado) - PUC-RJ.

OLIVEIRA, Lúcia Lippi. A questão nacional na Primeira República. São Paulo: Brasiliense, 1990.

ORTIZ, Renato. Cultura brasileira \& identidade nacional. São Paulo: Brasiliense, 1985.

PERLMAN, Janice. O mito da marginalidade: favelas e políticas no Rio de Janeiro. Rio de Janeiro: Paz e Terra, 1977.

POLLAK, Michel. Memória, esquecimento, silêncio. Estudos Históricos, Rio de Janeiro, n.3, 1988.

SUSSEKIND DE MENDONÇA, Edgard. A Escola Regional de Meriti (realizações e projetos). In: ÁLVARO ALBERTO, Armanda. A Escola 
Regional de Menti (documentário): 1921-1964. Rio de Janeiro: MEC, INEP, CBPE, 1968.

TRINDADE Raquel. Na festa de despedida. In: ÁLVARO ALBERTO, Armanda. A Escola Regional de Meriti (documentário): 1921-1964. Rio de Janeiro: MEC, INEP, CBPE, 1968.

VELHO, Gilberto. Memória, identidade e projeto: uma visão antropológica. Tempo Brasileiro, Rio de Janeiro, n.95, 1988.

VENANCIO FILHO, Francisco. A Escola Popular (Escola Regional de Meriti). In: ALVARO ALBERTO, Armanda. A Escola Regional de Meriti (documentário): 1921-1964. Rio de Janeiro: MEC, INEP, CBPE, 1968.

Recebido em 15 de junho de 1994.

Ana Chrystina Venancio Mignot é professora da Universidade do Estado do Rio de Janeiro (UERJ) e doutoranda do Programa de PósGraduação em Educação da Pontifícia Universidade Católica do Rio de Janeiro (PUC/RJ).

The analysis of the educational experience of Armanda Álvaro Alberto at the Escola Regional de Meriti, where for the first time in Brazil efforts were made for the integration between school and Community through the creation of a Mothers Association, indicated the relevance of a question that might seem minor at first sight: thefrequent changé of the name of the school. The different names, while expressions of the search for an educational identity, served as guide Unes for the understanding of the history of the school and of the life-history ofitsfounder and her companions at the Associação Brasileira da Educação. The different names also testify to the importance of the school for the Community of Caxias in the twenties and thirties.

L 'analyse de l 'experiencepédagogique d 'Armanda Álvaro Alberto à l 'Ecole Régionale de Meriti oi/ lespremiers efforts visant l 'integration de l 'école à Ia communauté ont étéfaits grâce à là formation du premier 
Cercle de Mères - cercle dont l 'objectif était de réaliser ce projet éducatif rénovateur - a soulève une question mineure et même négligeable: les changements successifs du nom de l 'école. Les noms, en tant qu 'expression $d$ 'une identité pédagogique donnée qui s 'est constituée à travers le temps, ont servi de fil conducteur pour retracer là trajectoria d 'une école, de sa fondatrice et des collègues de VAssociation Brésilienne d'Éducation $(A B E)$ et du role important de cette école au sein de là communauté de Caxias, en particulier dans les années 20 et 30.

El análisis de là experiência pedagógica de Armanda Álvaro Alberto en là Escuela Regional de Meriti — donde se desarrollaron los esfuerzos iniciales de integración escuela-comunidad a través del primer Círculo de Madres - , buscando dar sentido al proyecto educativo renovador, senaló là existência de un tema menor y que permanecia negligenciado: los câmbios sucesivos del nombre de là escuela. Los nombres, como expresión de una determinada identidad pedagógica, sirvieron de hilo conductorpara deshilar Ia trayectoria de là escuela, de su fundadora y companeros de là Asociación Brasilena de Educación (ABE)y también su importância en là comunidad caxiense, especialmente durante los anos 20 y 30 . 